\title{
FEAR-OF-MISSING-OUT BEHAVIOR PHENOMENA: A BIBLIOMETRIC ANALYSIS
}

\author{
Prio UTOMO \\ Universitas Multimedia Nusantara, Tangerang, Indonesia \\ prio.utomo@umn.ac.id \\ Florentina KURNIASARI \\ Universitas Multimedia Nusantara, Tangerang, Indonesia \\ florentina@umn.ac.id \\ Ade Kris YUDIONO \\ Universitas Multimedia Nusantara, Tangerang, Indonesia \\ kristianus@lecturer.umn.ac.id
}

\begin{abstract}
The purpose of this article is to review the current state, trend, and direction of Fear of Missing Out (FOMO) behavior research in various disciplines. There are 276 articles bibliography data extracted from Scopus Index Database in between year 2011-2021. Several analytic tools were used to seek key trends and bibliometric cooccurrence analysis. The result indicated that (1) the trend of FOMO-related research only emerged and trending up on the year 2015 despite their early appearance in 2004 (2) there is limited research on this topic with centrality in only several articles and authors. (3) the current research focuses on five clusters of research on the role of social media on FOMO, cause and effect of FOMO behavior, social network engagement on particular social network sites and the topic of social support and self-report on adolescents on FOMO. The study also opens a wide opportunity to other applications related to human and technology dynamic development such as social media fatigue, problematic smartphone use, mobile phone addiction, internet addiction disorder, covid-19, narcissism, decision making and gender.
\end{abstract}

Keywords: bibliometric; fear of missing out, FOMO; scopus; science map.

DOl: https://doi.org/10.24818/beman/2021.11.4-01

\section{INTRODUCTION}

The fear of missing out (FOMO) has received increasingly attention since the term coined by McGinnis in 2004 as he took MBA at the Harvard University (McGinnis, 2004). Since then, the term had been discussed extensively in many media all around the world, the Business Week commented that America top MBA programs were hit by pandemic called FOMO where symptoms include a chronic inability to turn down invitation to any invitation to build one's social network (McGinnis, 2020), The 
Oxford English Dictionary recognize the term in 2013 and Merriam-Webster Unbridged Dictionary included FOMO word three years after. The trend spread like a plague as Huffington Post stream out "Could Your FOO Kill You" as people seek for the cure (Mizrahi, 2014), and it last until these days with different phenomena due to vast technology proliferation and business environment disruption. KOMPAS (2021) reported and related FOMO with the E-Commerce Marketing, OCBC (2021) also reported the bad influence of FOMO in investment, and NY Times related FOMO with Covid-19 Pandemic (Gross \& Jimenez, 2021). The google trend analysis also shows increasing search on the topic globally since 2004 as depicted in FIGURE 1.

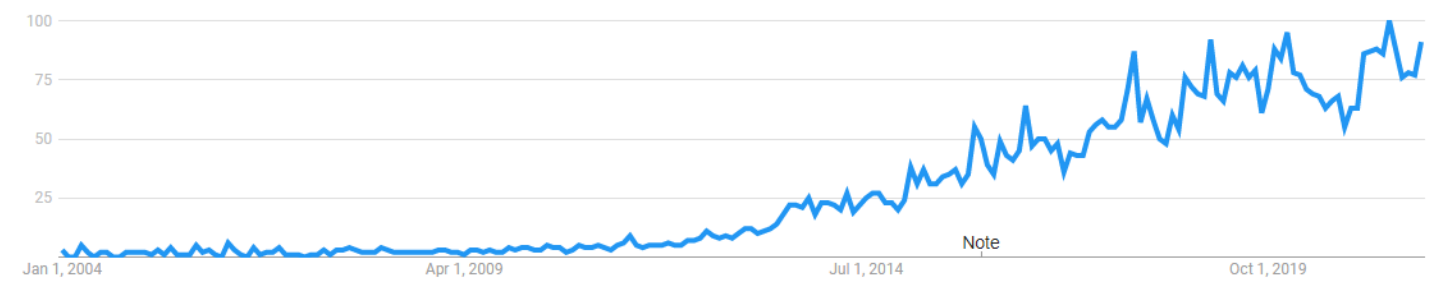

FIGURE 1. FOMO KEYWORD GOOGLE TRENDING

Source: FOMO Google Trends Analysis (2021)

Although the term is new, it is an old phenomenon. The history can be traced back to the study of Dr. Dan Herman, a marketing strategist, where he published the first academic paper related to FOMO in 2000. He mentioned that in the modern society especially in the post-modern era, the consumers are exposed with a lot of options where undermine the absolute truth or the right way as internal aspect of decision making, not mentioning the external pressures. Back at that day, people have more than one career in several organization (Herman, 2000), people want to have-it-all mindset that bring them into the paralyzed state where one cannot make any decision at all. FOMO is a dominant behavior that impacting children, adolescent and $70 \%$ of adults in developed countries (Malik et al., 2021; Schreckinger, 2014).

Despite the trend and the wide impact, the study direction and research regarding FOMO is still unclear and rare. Based on the Scopus Database in 2021 there are only around 276 publications that research on this topic which can initiate new research inquire that will be responded by this study. Thus, this research will review research in the related to FOMO phenomena using science mapping review methodology by understanding the key growth trends in research on FOMO, including authors and documents that have greatest impact on citation, the intellectual structure of the knowledge based and 
what topics in FOMO literature have been studied with greatest frequency and currently attracting the greatest attention with proposition to future research stream.

This study provides theoretical and practical contribution in several ways. Theoretically, it provides understanding of factors related to FOMO and it provide opportunities to understand new theory perspective through relationships between those factors for more depth and breadth future research. Practically, by understanding more deeper on this topic, intervention can be made to prevent and recover the society in general on dealing with this phenomenon.

\section{LITERATURE REVIEW}

\subsection{Bibliometric}

Bibliometric is used to summarize the wide range of bibliometric studies as part of the library and information science (Martínez-López et al., 2018). It is a qualitative method that used by scholar to understand emerging trends in article and journal, collaboration pattern between scholar and countries including exploring the intellectual structure of specific domain in the literature (Donthu et al., 2021). There are two categories of bibliometric categories: (1) performance analysis that focus on the analysis of research contribution. There is plenty way measure of the performance analysis e.g., total publications, number of active years of publication and productivity per active year of publication can be used to measure the publication-related metrics while h-index, g-index, citations perf cited publication can be used as citation and publication metric. (2) science map whereas focuses on the relationships between research constituents where it builds the intellectual interaction and structure connection between researchers. The science mapping technique comprises of citation analysis, co-citation analysis, bibliographic coupling, co-word analysis, and co- authorship analysis (Donthu et al., 2021) where citation relationship, keyword co-occurrence relationship and co-authorship relationship are the most commonly studied done (Van Eck \& Waltman, 2014). The bibliometric visualization is used to visualize the bibliometric network, it emphasizes several approaches like distance-based approach, graph-based approach and timeline-approach, visualization, and self-organizing maps.

\subsection{FEAR OF MISSING OUT (FOMO)}

The FOMO is defined as "An Anxiety-driven urge to hold out for something better based on the perception that a more favorable alternative or choice might exist" or "A compulsion to preserve option value that delays decision-making or postpone it indefinitely" (McGinnis, 2020).

The self-determination theory (SDT) is underpin the FOMO concept (Elhai et al., 2021). The SDT was developed by Ryan \& Deci (2000) that mentioned that one's motivation determined by the perceived of 
competence, autonomy and relatedness which when satisfied can result to enhanced self-motivation and mental health and if dissatisfied will result to diminished of motivation and well-being. Przybylski et al. (2013) stated that the intrinsic motivation - where it is concern with energy, direction, persistence and equifinality from inside of a person - could promote mental health and that intrinsic motivation is best promoted when one feels socially connect with other. FOMO has been related to SDT proposing that FOMO caused by the social unmet relatedness needs that can drive intrinsic motivation dan drive down motivation of adolescent and adult (Elhai et al., 2021). Due to the purpose of this research and above literature review, this research is addressing the following research questions $(R Q)$ :

RQ1: What is article publication and citation by time on FOMO topic between 2011-2021?

RQ2: What authors and document in the literature that have the great impact on citation related to FOMO in Scopus?

RQ3: What is the intellectual structure of knowledge based of FOMO topic on Scopus?

\section{RESEARCH METHODS}

In general, there are three steps on the protocol of the research by integrating Preferred Reposting Items for Systematic Review and Meta-Analysis (Moher et al., 2009) and Research Positioning and Trend Identification toolbox (Ranjbar-Sahraei \& Negenborn, 2017) as depicted in : (1) Data Collection and Screening, where authors access academic database and search systems based on criteria e.g., authors, title, abstract and keywords. The search is using word "fomo" to identify the relevant title, abstract and keywords. (2) Analysis A thorough review of available studies was conducted on the topic of FOMO (fear of missing out) using descriptive analysis and VOS Viewer software to create and develop bibliometric maps, as well as identifying cluster and associated reference networks. (3) Communicate and report the result in response to the research questions which will be elaborated in Section IV of this paper. 


\begin{tabular}{|c|c|c|}
\hline $\begin{array}{l}\text { Data Collection and } \\
\text { Screening }\end{array}$ & Data Analysis & Report the Result \\
\hline $\begin{array}{l}\text { Initial Search } \\
\text { Data } n=302 \\
\text { Screened Data } \\
n=276 \text { due to } \\
\text { duplication, irrelevance } \\
\text { and data format error }\end{array}$ & $\begin{array}{l}\text { Descriptive Analysis: } \\
\text { Citation Analysis and } \\
\text { Trend } \\
\text { Tools: } \\
\text { Scopus Analytic and } \\
\text { Excel } \\
\text { Bibliometric Analy sis: } \\
\text { Scientific Mapping } \\
\text { Tools: } \\
\text { VOSViewer } \\
\text { - Citation Analysis } \\
\text { - Co-Citation }\end{array}$ & $\begin{array}{l}\text { Descriptive Trends in the } \\
\text { Scopus } \\
\text { Analysis of Influential } \\
\text { Authors and Influential } \\
\text { Documents at Scopus } \\
\text { Intellectual FOMO } \\
\text { Knowledge Base }\end{array}$ \\
\hline
\end{tabular}

FIGURE 2. RESEARCH METHODS IN BIBLIOGRPAHY ANALAYSIS

Source: Adapted from Moher et al. (2009) and Ranjbar-Sahraei \& Negenborn (2017)

\subsection{Data collection and screening}

The Scopus database index was used as a source of the bibliometric study. Despite the growing development of publication database indexing such as Web of Science (WoS), Scopus, Dimension, and Google Scholar, there are two of them that most prominent, Web of Science and Scopus have been the most widely used databases for bibliometric analysis (Singh et al., 2021). Mongeon \& Paul-Hus (2016) on their analysis noticed that Scopus has larger coverage on Social Science, Arts and Humanities compared with the WoS. Scopus has more coverage in Europe and Asia (Ball, 2018) including in Indonesia where Scopus is more widely accepted and recognized as it is used as cornerstone and benchmark on the publication quality for Indonesian's Higher Education, universities and scholars as they measure research and publication performance by number of scholars and journal published with Scopus index (Siregar \& Rakhmani, 2016).

\subsection{Data analysis}

The bibliographic data such as citation Information, bibliographic information, abstracts and keywords and reference are exported and saved for subsequence data analysis which includes descriptive statistic as well as advanced bibliographic analysis including citation, co-citation and visualization of similarities using author co-citation keyword co-occurrence. The Scopus Analytical tools, Excel and VOS Viewer bibliometric software was used to conduct the bibliometric analysis. 


\section{RESULTS AND DISCUSSION}

\subsection{Descriptive trends in the Scopus}

The descriptive analysis of Scopus publication and citation distribution in the past ten years (2011-2021) shows an increasing trend. The article by Przybylski et al. (2013) become the cornerstone of the current publication as it is cited 714 times until now. The publication with FOMO topic raised up since 2017 until now where in 2017 there was thirteen publications and growing until 2021 with total 81 published paper as depicted in FIGURE 2. The citation per year publication fluctuated until now with trend up with the next spike in 2017 where there were 1086 citations. The topic of Social Networking sites and addition had raised- up (Kuss \& Griffiths, 2017) published their findings.

\subsection{Scopus influential authors and influential document analysis}

The top 10 most influential by number of citation are listed in the TABLE 1 with most cited article was written by Przybylski et al. (2013). The country of origin of these authors are majority from Europe e.g., United Kingdom (UK), Spain, Dutch, German until recently several authors from United Stated of America (USA), Israel and Asia such as Vietnam and China.

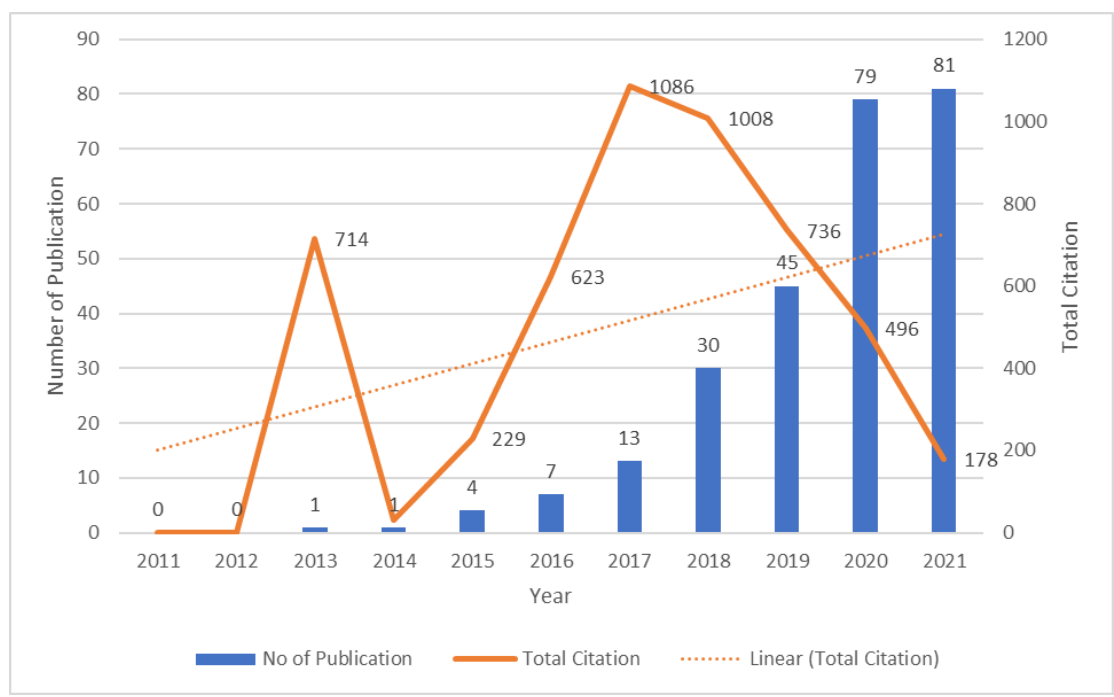

FIGURE 3. TRENDS IN NO OF PUBLICATION AND TOTAL CITATION BETWEEN 2011-2021

Source: Scopus Data Trending by Authors (2021) 
TABLE 1. SCOPUS MOST INFLUENTIAL FOMO PUBLICATION BY CITATION

\begin{tabular}{|c|c|c|c|c|}
\hline Cited by & First Author & Year & Title & Country \\
\hline 713 & Przybylski et al. (2013) & 2013 & $\begin{array}{l}\text { Motivational, emotional, and behavioral correlates } \\
\text { of fear of missing out }\end{array}$ & UK \\
\hline 269 & Kuss \& Griffiths (2017) & 2017 & $\begin{array}{l}\text { Social networking sites and addiction: Ten } \\
\text { lessons learned }\end{array}$ & UK \\
\hline 229 & Oberst et al. (2017) & 2017 & $\begin{array}{l}\text { Negative consequences from heavy social } \\
\text { networking in adolescents: The mediating role of } \\
\text { fear of missing out }\end{array}$ & SPAIN \\
\hline 211 & Blackwell et al. (2017) & 2017 & $\begin{array}{l}\text { Extraversion, neuroticism, attachment style and } \\
\text { fear of missing out as predictors of social media } \\
\text { use and addiction }\end{array}$ & USA \\
\hline 205 & Beyens et al. (2016) & 2016 & $\begin{array}{l}\text { "I don't want to miss a thing": Adolescents' fear of } \\
\text { missing out and its relationship to adolescents' } \\
\text { social needs, Facebook use, and Facebook } \\
\text { related stress }\end{array}$ & DUTCH \\
\hline 187 & Dhir et al. (2018) & 2018 & $\begin{array}{l}\text { Online social media fatigue and psychological } \\
\text { wellbeing-A study of compulsive use, fear of } \\
\text { missing out, fatigue, anxiety, and depression }\end{array}$ & VIETNAM \\
\hline 160 & Wolniewicz et al. (2018) & 2018 & $\begin{array}{l}\text { Problematic smartphone uses and relations with } \\
\text { negative affect, fear of missing out, and fear of } \\
\text { negative and positive evaluation }\end{array}$ & USA \\
\hline 148 & Alt (2015) & 2015 & $\begin{array}{l}\text { College students' academic motivation, media } \\
\text { engagement and fear of missing out }\end{array}$ & ISRAEL \\
\hline 105 & Wegmann et al. (2017) & 2017 & $\begin{array}{l}\text { Online-specific fear of missing out and Internet- } \\
\text { use expectancies contribute to symptoms of } \\
\text { Internet-communication disorder }\end{array}$ & GERMANY \\
\hline 103 & $\begin{array}{l}\text { Barry C.T (Barry et al., } \\
\text { 2017) }\end{array}$ & 2017 & $\begin{array}{l}\text { Adolescent social media use and mental health } \\
\text { from adolescent and parent perspectives }\end{array}$ & USA \\
\hline
\end{tabular}

Source: Summarized by Authors (2021)

The Scopus analytic as depicted in TABLE 2 mentioned that Jon D. Elhai wrote 18 articles in the past 10 year follow by Christian Montag, and Haibu Yang with 8 articles. Mandeep Dhir wrote 7 articles followed by Alt Dorit, Lin Lei and Ping Wang with 8 articles. Different than the top author by citation (TABLE 1. SCOPUS MOST INFLUENTIAL FOMO PUBLICATION BY CITATIONTABLE 1), the universities affiliation came from other part of the world (USA and China). 
Utomo, P., Kurniasari, F., Yudiono, A.K.,

FEAR-OF-MISSING-OUT BEHAVIOR PHENOMENA: A BIBLIOMETRIC ANALYSIS

TABLE 2. SCOPUS TOP AUTHOR BY NUMBER OF ARTICLES

\begin{tabular}{|c|l|l|}
\hline $\begin{array}{c}\text { No } \\
\text { Article }\end{array}$ & Scholar Name & University \\
\hline 18 & Jon D. Elhai & University of Toledo, Toledo Ohio, USA \\
\hline 9 & Christian Montag & Ulm University, German \\
\hline 9 & Haibo Yang & Tianjin Normal University, Tianjin, China \\
\hline 8 & Mark D. Griffiths & Nottingham Trent University \\
\hline 8 & Dmitri Rozgonjuk & University of Tartu, Estonia \\
\hline 7 & Amandeep Dhir & University of Agder, Norway \\
\hline 6 & Alt Dorit & Kinneret College on the Sea of Galilee, Israel \\
\hline 6 & Li Lei & Renmin University of China \\
\hline 6 & Ping Wang & Huazhong University of Science and technology (HUST) \\
\hline
\end{tabular}

Source: Scopus Analysis by Authors (2021)

\subsection{Intellectual FOMO knowledge base}

There have been several attempts in recent years to conduct a comprehensive analysis of the particular knowledge domain, to trace its historical evolution, to map its conceptual structure, and to assess its strengths and limitations (Nerur et al., 2008). And in this study co-occurrence type of analysis were used to understand the relationship between keyword in the database index. VOS Viewer were set at minimum five number keywords occurrences and there are 83 keywords to be selected. The result show that there are five clusters of focus science in indicate by the color of the node as depicted in FIGURE 4. 


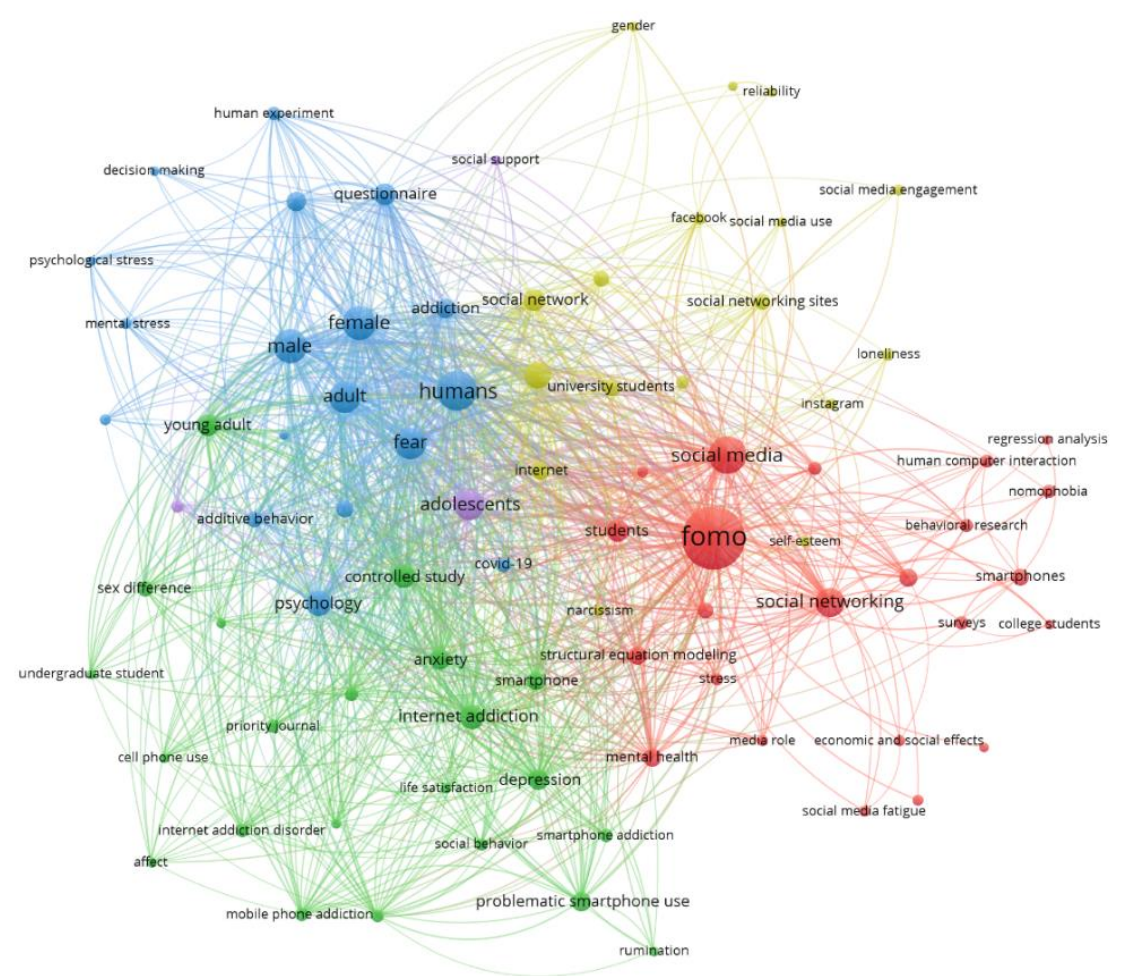

FIGURE 4. NETWORK VISUALIZATION

Source: Visualized by Authors (2021) using Vos Viewer

There are several words that have significant weight compared with others. Words such as FOMO, social media, fear, phycology, adults, human male, and female had a large diameter of node. The distance between node represents the relatedness between words. The nearest node with FOMO word is related to social network, social media, students.

The temporal co-word analysis was constructed to study the time distribution of keywords in relation the publishing data. The Yellow bubble represent the most recent issue of interest in this discipline while the darker blue presents the previous time. This map's interpretation is based on the size of the bubble (frequency), its color (recency) and its location (relationship to other topics). From the Overlay visualization (FIGURE 6. OVERLAY VISUALIZATION), there are several recent topics regarding FOMO such as social media fatigue, problematic smartphone use, mobile phone addiction, internet addiction disorder, covid-19, narcissism, decision making and gender as colored with yellow color.

The study also noted five topical cluster focused on the role of social media that linked to keywords such as behavioral research, social media, nomophobia, phubbing, social networking, social networking sites, student motivation, mental health, and problematic internet use. Two social media platform also being mentioned in this study which are Facebook and Instagram. The second cluster is related to the 
cause of FOMO that link to words such as anxiety, depression, disease association, rumination, sex difference, and social behavior. The third cluster is related to the psychology result that link to words such as psychological stress, mental stress, human experience, decision making, fear, covid-19, addiction. The fourth cluster is about specific study on particular social network engagement like in Facebook and Instagram. And the last cluster is about the FOMO related to social support and selfsupport on adolescents.

\subsection{Topical FOCI of the FOMO}

To understand the theme covered in this study, co-word analysis was use as initial step to determine the most frequently used terms. ASS depicted din the density map (FIGURE 5), the most frequently occurring keywords and respective total link strength were FOMO (occurrence 192, strength 1121), humans (occurrence 81 , strength 948), female (occurrence 57 , strength 770 ), male (occurrence 57 , strength 763), adult (occurrence 49, strength 685), fear (occurrence 50,678) and social media (occurrence 72 , strength 571). These finding reinforce the result of the previous keyword occurrences analysis result.

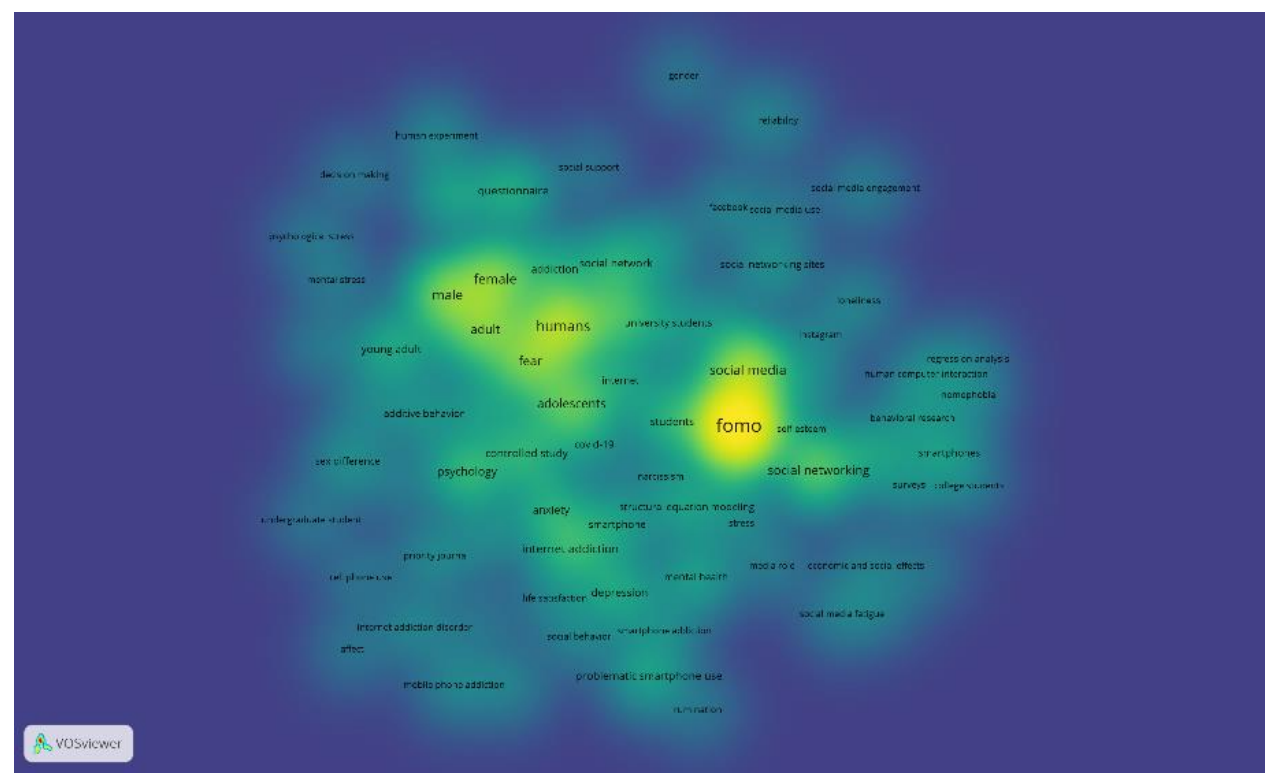

FIGURE 5. DENSITY MAP VISUALIZATION

Source: Visualized by Authors (2021) using VosViewer

The article publication and citation by time on FOMO topic between 2011-2021 as analyzed at FIGURE 3 depicts trending up both on published article and citation related to FOMO. There is no publication prior 2012. The most cited document so far is article written by Przybylski et al (2013) in 2013 with total 
714 citations so far. The topic start to get traction on 2015 onward especially in topic related to social media.

As for the most productive scholar that research FOMO, Jon D. Elhai from University of Toledo, Toledo Ohio, USA wrote 18 articles so far. Elhai was the first scholar that introduce the SDT approach to frame FOMO phenomena.

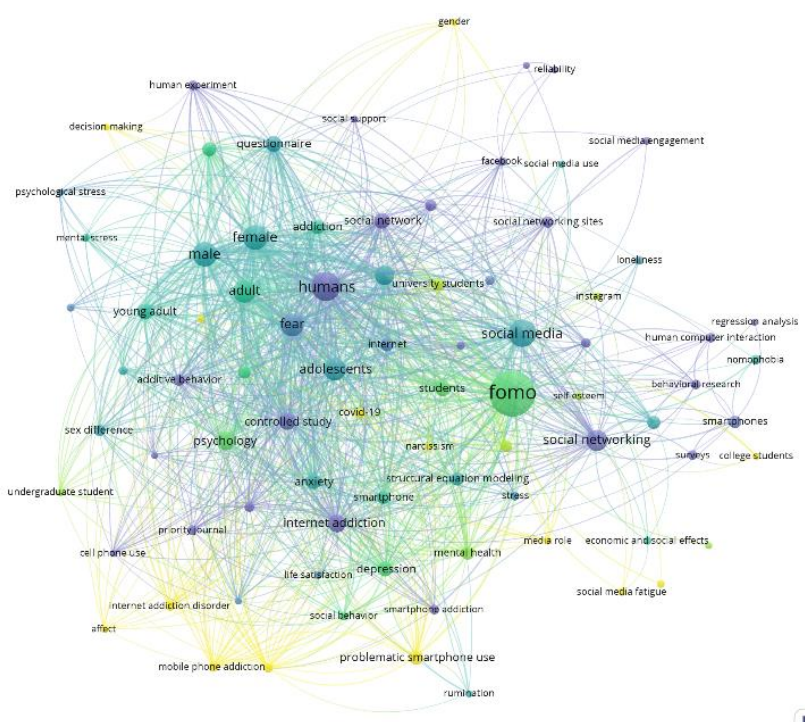

FIGURE 6. OVERLAY VISUALIZATION

Source: Visualized by Authors (2021) using VosViewer

The intellectual structure of FOMO Knowledge based in Scopus showed that there are five clusters of focus that could become the research proposition on future research. They are the the role of social media and networking to, cause and effect of FOMO from psychology, social network engagement like in Facebook and Instagram, and last the social support.

\section{FUTURE RESEARCH, LIMITATION, AND CONCLUSION}

\subsection{Research proposition for future studies}

There are several research proportions for future studies from the networks visual analyze and currently still lack and have limited publication such as social media fatigue, problematic smartphone use, mobile phone addiction, internet addiction disorder, covid-19, narcissism, decision making and gender as colored with yellow color. Looking at the trend as FOMO related to psychological aspect of human, the 
topic related to human behavior cause by the internal and external aspect of human will be relevant with this topic.

\subsection{Limitations}

This study only uses bibliographic information from Scopus Database, the combination between Scopus and WoS will provide wider view on the trends and visualization of this study. The access to WoS is limited due to subscription of that index database publisher which limit the bibliometric information that can be retrieved. The analysis also will be limited to the tools used to analyze which is VOS Viewer.

\subsection{Conclusions}

Despite the first appearance of FOMO in 2004 only just until recently the topic trending up as the development of Internet and adoption of social media that change the behavior of people especially adolescent. The Scopus Database Index on article about FOMO has been trending up in the past 10 years starting in 2015 with several central article and topics especially in psychology and social media. It opens new horizon and opportunity in this phenomenon as it is trending up and the human behavior changed as the proliferation of technology.

\section{REFERENCES}

Alt, D. (2015). College students' academic motivation, media engagement and fear of missing out. Computers in Human Behavior, 49, 111-119. https://doi.org/https://doi.org/10.1016/j.chb.2015.02.057

Ball, R. (2018). An Introduction to Bibliometrics: New Development and Trends. Chandos Publishing.

Barry, C. T., Sidoti, C. L., Briggs, S. M., Reiter, S. R., \& Lindsey, R. A. (2017). Adolescent social media use and mental health from adolescent and parent perspectives. Journal of Adolescence, 61, 111. https://doi.org/https://doi.org/10.1016/j.adolescence.2017.08.005

Beyens, I., Frison, E., \& Eggermont, S. (2016). "I don't want to miss a thing": Adolescents' fear of missing out and its relationship to adolescents' social needs, Facebook use, and Facebook related stress. Computers in Human Behavior, 64, 1-8. https://doi.org/https://doi.org/10.1016/j.chb.2016.05.083

Blackwell, D., Leaman, C., Tramposch, R., Osborne, C., \& Liss, M. (2017). Extraversion, neuroticism, attachment style and fear of missing out as predictors of social media use and addiction. Personality and Individual Differences, 116, 69-72. https://doi.org/10.1016/j.paid.2017.04.039

Dhir, A., Yossatorn, Y., Kaur, P., \& Chen, S. (2018). Online social media fatigue and psychological wellbeing -A study of compulsive use, fear of missing out, fatigue, anxiety and depression. International Journal of Information Management, 40, 141-152. https://doi.org/https://doi.org/10.1016/j.ijinfomgt.2018.01.012 
Donthu, N., Kumar, S., Mukherjee, D., Pandey, N., \& Lim, W. M. (2021). How to conduct a bibliometric analysis: An overview and guidelines. Journal of Business Research, 133(May), 285-296. https://doi.org/10.1016/j.jbusres.2021.04.070

Elhai, J. D., Yang, H., \& Montag, C. (2021). Fear of missing out (Fomo): Overview, theoretical underpinnings, and literature review on relations with severity of negative affectivity and problematic technology use. Brazilian Journal of Psychiatry, 43(2), 203-209. https://doi.org/10.1590/1516-4446-2020-0870

Gross, J., \& Jimenez, J. (2021). The 'Joy and Envy' of Vaccine FOMO - The New York Times. NY Times. https://www.nytimes.com/2021/04/06/health/covid-vaccine-jealousy.html

Herman, D. (2000). Introducing short-term brands: A new branding tool for a new consumer reality. Journal of Brand Management, 7(5), 330-340. https://doi.org/10.1057/bm.2000.23

KOMPAS. (2021). Kenali Strategi Marketing Fear of Missing Out (FOMO) dalam E-commerce. KOMPAS.Com. https://www.kompas.com/parapuan/read/532876881/kenali-strategi-marketingfear-of-missing-out-fomo-dalam-e-commerce

Kuss, D. J., \& Griffiths, M. D. (2017). Social networking sites and addiction: Ten lessons learned. International Journal of Environmental Research and Public Health, 14(3). https://doi.org/10.3390/ijerph14030311

Malik, A., Dhir, A., Kaur, P., \& Johri, A. (2021). Correlates of social media fatigue and academic performance decrement: A large cross-sectional study. Information Technology and People, 34(2), 557-580. https://doi.org/10.1108//TP-06-2019-0289

Martínez-López, F. J., Merigó, J. M., Valenzuela-Fernández, L., \& Nicolás, C. (2018). Fifty years of the European Journal of Marketing: a bibliometric analysis. European Journal of Marketing, 52(1-2), 439-468. https://doi.org/10.1108/EJM-11-2017-0853

McGinnis, P. J. (2004). Social Theory at HBS: McGinnis' Two FOs. The Harbus News Corporation. https://harbus.org/2004/social-theory-at-hbs-2749/

McGinnis, P. J. (2020). Fear of Missing Out: Practical Decision-making in a World of Overwhelming Choice. Sourcebooks. https://books.google.co.id/books?id=zPJixwEACAAJ

Mizrahi, G. (2014). Could Your FOMO Kill You? Huffington Post. https://www.huffpost.com/entry/fomo_b_5130364

Moher, D., Liberati, A., Tetzlaff, J., Altman, D. G., \& Grp, P. (2009). Preferred Reporting Items for Systematic Reviews and Meta-Analyses: The PRISMA Statement (Reprinted from Annals of Internal Medicine). Physical Therapy, 89(9), 873-880. https://doi.org/10.1371/journal.pmed.1000097

Mongeon, P., \& Paul-Hus, A. (2016). The journal coverage of Web of Science and Scopus: a comparative analysis. Scientometrics, 106(1), 213-228. https://doi.org/10.1007/s11192-015-17655

Nerur, S. P., Rasheed, A. A., \& Natarajan, V. (2008). The intellectual structure of the strategic management field: an author co-citation analysis. Strategic Management Journal, 29(3), 319-336. https://doi.org/https://doi.org/10.1002/smj.659

Oberst, U., Wegmann, E., Stodt, B., Brand, M., \& Chamarro, A. (2017). Negative consequences from heavy social networking in adolescents: The mediating role of fear of missing out. Journal of Adolescence, 55, 51-60. https://doi.org/https://doi.org/10.1016/j.adolescence.2016.12.008

OCBC. (2021). Apa itu Fomo? Pengertian dan Dampak Buruk pada Finansial. OCBC. https://www.ocbcnisp.com/en/article/2021/09/09/fomo-adalah 
Przybylski, A. K., Murayama, K., DeHaan, C. R., \& Gladwell, V. (2013). Motivational, emotional, and behavioral correlates of fear of missing out. Computers in Human Behavior, 29(4), 1841-1848. https://doi.org/https://doi.org/10.1016/j.chb.2013.02.014

Ranjbar-Sahraei, B., \& Negenborn, R. R. (2017). Research Positioning \& Trend Identification - a dataanalytics toolbox. In TU Delft.

Ryan, R. M., \& Deci, E. L. (2000). Self-determination theory and the facilitation of intrinsic motivation, social development, and well-being. In American Psychologist (Vol. 55, Issue 1, pp. 68-78). American Psychological Association. https://doi.org/10.1037/0003-066X.55.1.68

Schreckinger, B. (2014). The History of FOMO. Boston Magazine. https://www.bostonmagazine.com/news/2014/07/29/fomo-history/

Singh, V. K., Singh, P., Karmakar, M., Leta, J., \& Mayr, P. (2021). The journal coverage of Web of Science, Scopus and Dimensions: A comparative analysis. Scientometrics, 126(6), 5113-5142. https://doi.org/10.1007/s11192-021-03948-5

Siregar, F., \& Rakhmani, I. (2016). Global Development Network Working Paper Series Reforming Research in Indonesia: policies and practice Reforming Research in Indonesia: Policies and Practices (Issue 92). http://cipg.or.id/

Van Eck, N. J., \& Waltman, L. (2014). Visualizing Bibliometric Networks. In Measuring Scholarly Impact. https://doi.org/10.1007/978-3-319-10377-8_13

Wegmann, E., Oberst, U., Stodt, B., \& Brand, M. (2017). Online-specific fear of missing out and Internet-use expectancies contribute to symptoms of Internet-communication disorder. Addictive Behaviors Reports, 5(February), 33-42. https://doi.org/10.1016/j.abrep.2017.04.001

Wolniewicz, C. A., Tiamiyu, M. F., Weeks, J. W., \& Elhai, J. D. (2018). Problematic smartphone use and relations with negative affect, fear of missing out, and fear of negative and positive evaluation. Psychiatry Research, 262, 618-623. https://doi.org/https://doi.org/10.1016/j.psychres.2017.09.058 